\title{
A BIBLIOTECONOMIA E A CIÉNCIA DA INFORMAÇÃO NA TAXIONOMIA DAS CIÊNCIAS DE CHARLES SANDERS PEIRCE*
}

\section{Carlos Cândido de Almeida}

\section{Resumo}

Mostra a taxionomia das ciências desenvolvida por Charles Sanders Peirce (1839-1914) que divide as ciências em três ramos: ciências teóricas, ciências da revisão e ciências aplicadas. Detalha principalmente as ciências teóricas: a Matemática, a Filosofia e a Idioscopia. Discute também o conceito de Biblioteconomia e de Ciência da Informação e que segundo as definições e características, encontradas na literatura consultada, estão na condição de ciências aplicadas, direcionadas a problemas práticos da sociedade, ou seja, o problema de controle e disseminação da informação.

\section{Palavras-Chave}

Classificação das ciências; Ciência da informação; Biblioteconomia.

\section{THE LIBRARIANSHIP AND THE INFORMATION SCIENCE IN THE CHARLES SENDER PIERCE'S SCIENCE TAXONOMY}

\begin{abstract}
It shows the taxonomy of the sciences developed by Charles Sanders Peirce (1839-1914) which divides the science in three branches: theorical sciences, revision science and applied sciences. It details, meanly the theorical sciences: Mathematics, Philosophy and Idioscopy. It discuss also the concept of Librarianship and Information Science, according to definitions and caractheristics that were found in the consulted literature, are in the condition of applied science and directioned to pratical problems of the society, that is the problem of information control and dissemination.
\end{abstract}

\section{Keywords}

Science classification; Information science, Librarianship.

\footnotetext{
* Este artigo é parte do capítulo: Filosofia e Semiótica do Trabalho de Conclusão de Curso intitulado Semiótica, Internet e Interatividade: a interatividade dos portais BOL e UOL, apresentado em 2003.
} 


\section{INTRODUÇÃO}

O artigo tem por objetivo mostrar a taxionomia das ciências de Charles Sanders Peirce (18391914) e incluir a Biblioteconomia e a Ciência da Informação como ciências aplicadas. Além disso, aponta algumas direções para o início de uma discussão que pode vir a ser mais rica e gerar outras contribuições a partir das aproximações aqui realizadas, no sentido de visualizar estas duas áreas no conjunto das ciências. Para compreendermos onde se insere a taxionomia das ciências de Charles Sanders Peirce é necessário contextualizar alguns fatores que contribuíram para o desenvolvimento do pensamento do autor.

No dia 10 de setembro de 1839 nasceu em Cambridge, Massachusetts nos Estados Unidos, Charles Sanders Peirce. Ele contribuiu para a filosofia e as ciências ocidentais perscrutando diversas ciências, entre elas têm-se a lógica, a biologia, a geodésia, a geologia. Em toda sua vida não obteve muito sucesso acadêmico, sendo apenas poucas vezes convidado a ministrar aulas, na condição de professor assistente, na Universidade de Johns Hopkins, em Baltimore, nos Estados Unidos.

A conduta de Peirce o revela como um sujeito com a vida a serviço da ciência. Para ele, a ciência só pode ser levada à diante por pessoas engajadas na busca pela verdade, “[...] na vida dedicada à investigação da verdade, fruto de forte impulso para se penetrar na razão das coisas" (PIRES, 1999, p. 20).

Foi influenciado por muitos intelectuais que freqüentavam sua casa em reuniões com seu pai, Benjamim Peirce, matemático respeitado da época. Outro incentivo para Peirce foi o estudo a fundo da obra de Kant ( $A$ crítica da razão pura), que após anos de estudo a conhecia em minúcia (SANTAELLA, 1983, p. 19). Com 11 anos escreveu uma História da Química e aos 23 anos a Teoria Química da Interpretação. Colaborou decisivamente com a Lógica e insistiu até o final de sua vida para que esta fosse considerada uma ciência autônoma.

Essas e outras contribuições instigaram Peirce, no curso de sua vida, a montar uma taxionomia da ciência. Para Peirce "é através da observação que se apresenta qualquer forma de conhecimento, no entanto cada ciência tem seus caminhos para observação" (PIRES, 1999, p. 20). A definição de ciência e a própria ciência, para o autor, são coisas vivas, organizadas e 
levadas à frente por homens vivos e por isto não se devem classificá-las pelos estoques de conhecimentos que estão armazenados. A noção de ciência de Peirce difere a ciência-estoque da ciência-processo-ação.

Segundo Peirce (1980, p. 140):

Outra falha de muitas classificações - ou se não uma falha é pelo menos um projeto bastante diverso de um projeto suficientemente ousado que julgo necessário empreender - é que elas são classificações não da ciência, como ela existe, mas de conhecimento sistematizado conforme a esperança do classificador.

Peirce acreditava na ciência como a atitude de busca da verdade e, os homens que se empenham nesta investigação utilizando para isto todos os métodos possíveis de aplicação ao seu objeto de estudo, estes sim devem ser chamados de cientistas, pois "a vida da ciência reside na vontade de conhecer" (PEIRCE, 1980, p. 140). Para o autor a ciência na forma de conhecimento catalogado, sistematizado e estocado é ciência morta. A ciência é ação, é continuação, é processo. A classificação das ciências não deve seguir o princípio do conhecimento sistematizado, isto seria classificar a partir das evidências e do que está consolidado. A ciência como entidade viva, construída por homens de bem, só pode ser ação em processo.

Charles Sanders Peirce foi também o iniciador do Pragmatismo, e discordava da extensão da acepção do termo atribuída por seu amigo William James (1842-1910). Por isso, cunhou um termo mais adequado para, segundo ele, ser um instrumento para a filosofia, o pragmaticismo. Palavra considerada pelo autor feia, mas que assegurava o ideal de seu pragmatismo.

O pragmatismo busca verificar os significados dos pensamentos somando os efeitos práticos resultantes da ação destes pensamentos. Ou seja, “considerar os efeitos práticos que possam pensar-se como produzidos pelo objeto de nossa concepção. A concepção destes efeitos é a concepção total do objeto" (PEIRCE, 1980, p. 5). Pragmatismo seria um instrumento ou método para a filosofia clarificar seus argumentos. O conhecimento em certa medida está relacionado à ação humana, isto evidencia o aspecto prático também do conhecimento e da reflexão filosófica. O pragmatismo "[...] é um método capaz de determinar o verdadeiro sentido de qualquer conceito, doutrina, proposição, palavra, ou outro tipo de signo" (PEIRCE, 1980, p. 6). Com isso, o pragmatismo considera que as discussões filosóficas equivocam-se 
no uso e no sentido das palavras e somente o método de investigação pragmatista pode determinar o verdadeiro sentido e acepção correta das palavras e das teorias.

A máxima pragmatista sustenta que: "para determinar o sentido de uma concepção intelectual devem-se considerar as conseqüências práticas pensáveis como resultantes necessariamente da verdade da concepção; e a soma dessas conseqüências constituirá o sentido total da concepção" (PEIRCE, 1980, p. 7). Esta máxima foi replicada por Peirce por volta de 1905, numa carta endereçada a Mario Calderoni, em que dizia que esta postura era ultra-pragmatista (SILVEIRA, 1985, p. 6). Nota-se também que a concepção pragmatista peirceana refere-se a métodos de verificação da exatidão das idéias e dos conceitos, sua conformação com a realidade prática, incluindo, inclusive, a noção de conseqüências práticas para compreender o objeto referido em tais idéias ou conceitos. Nesse sentido, o pragmatismo distancia-se das proposições do utilitarismo de Jeremy Bentham (1748-1832) que, na compreensão comum, são encontrados como equivalentes ou muito semelhantes.

O pragmatismo consiste em estabelecer um método para que se alcance o significado dos conceitos intelectuais (VALENTE; BROSSO, 1999, p. 51). Teixeira Coelho (1999, p. 54-55) fornece uma contribuição ao resumir o que Peirce entendia por pragmatismo, renomeado de pragmaticismo. O pragmatismo tem como base que:

1) fenômenos experimentais são os únicos capazes de afetar a conduta humana; 2) a soma dos fenômenos experimentais implicados numa proposição constitui o alcance dessa proposição sobre a conduta humana; 3) o significado dessa proposição é exatamente essa soma de fenômenos experimentais. (COELHO, 1999, p. 54-55).

A experiência para Peirce não se resume às ocorrências físicas dos eventos, existem os fenômenos mentais que são suscetíveis de afetar a conduta humana.

Com a noção de continuidade da interpretação das idéias (signos), entendida como ação dos signos ${ }^{1}$ ou semiose, Peirce debate a noção de objetividade e verdade do conhecimento e do conhecimento científico, preanunciando o caráter falível e mutável tanto das teorias quanto dos conceitos. Com isso, lançou as bases de sua filosofia que se pautou principalmente no

\footnotetext{
${ }^{1}$ O signo na definição peirceana mais geral é um primeiro que se coloca em relação a um segundo para determinar um terceiro que é seu interpretante. Um signo representa alguma coisa, seu objeto, por este é determinado e apenas é concluído este processo de representação quando dá origem a um outro tipo de signo que interpreta o primeiro, chamado de interpretante.
} 
falibilismo. Segundo Valente; Brosso (1999, p. 39) "suas idéias eram o fruto de trinta anos, as quais reunia sob a designação de 'falibilismo', conceito de onde brotava sua filosofia e de um intenso desejo de investigação". O falibilismo é a teoria do crescimento contínuo do universo e da mente humana (SANTAELLA, 1983, p. 25). Assim, qualquer proposição a respeito da realidade, mesmo a mais objetiva está sujeita a modificação, seja da ordem das leis ou da ordem dos próprios fenômenos. Peirce procurou contribuir, com suas bases teóricas, para uma "inteligência científica", que ele preconizou como necessária para a redução dos problemas da filosofia e da ciência.

Charles Sanders Peirce faleceu em 1914, deixando uma obra catalogada que ultrapassa 90.000 páginas, destas, boa parte ainda não editada.

Por ora, é necessário apontar outros caminhos da filosofia de Charles Sanders Peirce, pelo menos suas contribuições à classificação das ciências. Além disso, buscar-se-á caracterizar a partir de um conjunto de autores a Biblioteconomia e a Ciência da Informação como detentoras de princípios práticos, norma constante nas Ciências Aplicadas caracterizadas por Peirce.

\section{A TAXIONOMIA DAS CIÊNCIAS DE PEIRCE: as ciências teóricas}

Como conta Pires (1999, p. 20), Peirce tomou de Comte (1798-1857) a idéia de que as ciências dependem umas das outras para desenvolverem, ou seja, as ciências mais formais transferem princípios e teorias para as ciências mais aplicadas e/ou específicas, enquanto que as ciências mais práticas dão objetos para a indagação e a investigação científica, realizadas pelas ciências teóricas.

As ciências, inicialmente foram divididas por Peirce em três ramos: as Ciências da Descoberta, as Ciências da Revisão e as Ciências Práticas. As Ciências da Descoberta empenham-se na busca pela verdade mais radical do que as outras ciências, estão no caminho das questões gerais e abstratas. As Ciências da Revisão funcionam como mediadoras entre as Ciências da Descoberta e as Ciências Aplicadas, elas atuam na adaptação e transferência dos conhecimentos originados nas ciências gerais com a finalidade de aplicação destes 
conhecimentos pelas Ciências Aplicadas. Preocupar-se com as situações e casos isolados é o objetivo das Ciências Aplicadas.

Posteriormente, Peirce agrupa esses três grandes ramos em apenas dois: Ciências Teóricas e Ciências Aplicadas, sendo que as Ciências Teóricas compreendem as Ciências da Descoberta e as Ciências da Revisão (ver Figura 1). A primeira das Ciências Teóricas é a Matemática que estuda o mundo real e qualquer mundo logicamente possível (PIRES, 1999, p. 20). Como explica Santaella (1983, p. 24):

A matemática é observativa na medida em que monta construções na imaginação de acordo com preceitos abstratos, passando, então, a observar esses objetos imaginários para neles encontrar relações entre partes que não estavam especificadas no preceito da construção.

As hipóteses da Matemática podem relacionar-se ou com uma coleção finita ou infinita, daí a divisão da Matemática em Coleções Finitas e Coleções Infinitas. As Coleções Finitas dividem-se em Lógica da Matemática e Teoria das Séries Finitas. As Coleções Infinitas desdobram-se em Aritmética e Cálculo.

O segundo ramo das Ciências da Descoberta é o da Filosofia que visa à verdade a partir das observações do universo e das experiências do homem, "ela se limita, porém, ao tanto de verdade que pode ser inferido da experiência comum. É uma ciência fundamentalmente observativa pois que visa colocar em ordem aquelas observações que estão ao aberto para todo homem, todo dia e hora" (SANTAELLA, 1983, p. 25). A Filosofia abrange: a Fenomenologia, as Ciências Normativas e a Metafísica. Para a Fenomenologia atribui todo o estudo dos fenômenos, desde classificação, caracterização e validação no âmbito do real; a fenomenologia é a "[...] mais primitiva das ciências positivas. Quer dizer que não se baseia no respeitante aos princípios sobre qualquer ciência positiva" (PEIRCE, 1980, p. 14). As Ciências Normativas estudam as condutas de uma mente que aprende pela experiência e assim intentam entendê-la e a Metafísica ocupa-se das questões referentes à realidade do mundo.

As Ciências Normativas compreendem a Estética, a Ética e a Lógica ou Semiótica. A Estética intenta os ideais últimos, busca analisar aquilo que não tem razão futura, se bem que existe “[...] algumas dúvidas quanto à existência de uma ciência normativa do belo" (PEIRCE, 2000, p. 202). A Ética, para Peirce, é a ciência que está voltada para a determinação do certo e do 
errado na conduta, para chegar a concretizar aquilo que se considera admirável. A Lógica ou Semiótica está centrada na pesquisa de procedimentos, normas e métodos para conhecer uma mente que aprende pela experiência. Sendo que todo pensamento e consciência só dão-se mediante a manipulação de signos, com isso, fica evidente que a semiótica deve abarcar as relações de lei que norteiam o processo dos signos.

Segundo Peirce (1980, p. 37) "a ciência normativa trata das leis que conformam as coisas às finalidades; a estética considera as coisas cujos fins encarnam qualidades de sensação; ética aquelas coisas cujos fins residem na ação - e a lógica, as coisas cujo fim é representar algo [...]" e está longe de ser uma Ciência Prática, ela está dentro das Ciências Teóricas, pois maneja as leis da relação dos fenômenos com os seus fins (PEIRCE, 2000, p. 198-199). Para a Estética é necessário abrir o espírito para apreender, através das sensações e das qualidades dos objetos da experiência que surgem. A Ética estabelece normas e caminhos ideais para seguir, mas depende que os fatos e os acontecimentos estejam presentes à admiração. Já a Lógica ou Semiótica pode ser entendida como a Ciência Normativa que procura estabelecer os caminhos que levam uma mente a representar.

Em suma, a ética apóia-se numa doutrina que, sem considerar o que deva ser nossa conduta, divide os estados idealmente possíveis das coisas em duas classes, admiráveis e in-admi-rá-veis, e empenha-se em definir precisamente o que é que constitui a admirabilidade de um real. [...] Chamo esta investigação de Estética, porque se diz geralmente que as três ciências normativas são lógica, ética e estética, [...]. É evidentemente a [a estética] ciência normativa básica que se deve apoiar a ética, que por seu turno sobrepujada pela doutrina da lógica. (PEIRCE, 1980, p. 14).

Todo o estudo de nossa admiração é objeto da Estética, e o que é admirado em certa medida pode ser considerado bom ou mau, levando à investigação dos fins últimos da admiração, a Ética. Por fim, validar ou não verdades aceitas eticamente e representar o conteúdo destas verdades são problemas da Lógica ou Semiótica.

A terceira ciência filosófica é a Metafísica, contando com a Ontologia, a Metafísica-Física e a Metafísica da Religião. Segundo Pires (1999, p. 22) “a primeira e a terceira põem-se a responder questões referentes a Deus, à liberdade e à imortalidade, enquanto a segunda responde questões sobre o tempo, espaço e sobre as leis da natureza e da matéria”. 
A última ciência dentro das Ciências da Descoberta é a Idioscopia, é nomeada também de Ciências Especiais. As Ciências Especiais utilizam métodos e instrumentos que extrapolam o poder dos sentidos para verificação das verdades e exigem modos de observação especiais (PIRES, 1999, p. 22; SANTAELLA, 1983, p. 25).

Segundo Correia (2002, p. 347) as Ciências Especiais ou Idioscópicas são subdivididas em subclasses, onde cada classe exerce uma função conforme o nível:

[...] nível nomological (nomológico), caracterizado como o estudo das leis gerais; nível classificatory (classificatório) estudo dos tipos gerais de fenômenos, sua formação e crescimento; nível descriptive (descritivo), que busca explicar fenômenos particulares e individuais.

A Idioscopia divide-se em Ciências Físicas ou Fisiognose e Ciências Psíquicas ou Psicognose. Dentro das Ciências Físicas encontra-se a Física Nomológica que estuda as leis que regem a natureza, mais especificamente, o estudo dos fenômenos físicos e depende de princípios criados na Metafísica e na Matemática. Outro ramo das Ciências Físicas é a Física Classificatória que descreve as formas físicas e as classifica, como a Biologia; procura explicar os fenômenos tomando como base as teorias propostas pela Física Nomológica. A Física Descritiva é a terceira Ciência Física e está fundamentada nas duas anteriores. A Física Descritiva enseja descrever fenômenos individuais, por exemplo, a astronomia (PIRES, 1999, p. 22).

As Ciências Psíquicas ou Psicognose (Ciências Humanas em geral) desmembram-se em Psíquica Nomológica, Psíquica Classificatória e Psíquica Descritiva. A Psíquica Nomológica, segundo Pires (1999, p. 22), “[...] é responsável pelos fenômenos mentais, suas leis e pelo descobrimento de seus elementos mais gerais (Psicologia experimental, por exemplo), se fundamenta na Fenomenologia, Lógica, Metafísica e Biologia (uma subdivisão da física classificatória)". A Psíquica Classificatória tem a finalidade de explicar os princípios psicológicos dos produtos da mente, como a Lingüística, a Psicologia Geral, a Sociologia Geral e a Economia Geral (CORREIA, 2002, p. 347). A última das Ciências Psíquicas é a Psíquica Descritiva, tem por tarefa descrever as manifestações, os atos e as ações individuais de uma mente; enquadram-se neste ramo das ciências a História, a Geografia, a Biografia e a Crítica (PIRES, 1999, p. 22; CORREIA, 2002, p. 347). 
Feito uma breve abordagem das Ciências Teóricas é necessário discutir a Biblioteconomia e a Ciência da informação segundo suas características e definições como pertencentes do ramo das Ciências Aplicadas, pois são das mais abstratas que tomam os conceitos mais gerais para aplicação.

\section{AS CIÊNCIAS APLICADAS: a Biblioteconomia e a Ciência da Informação}

As Ciências Aplicadas são consideradas aquelas que fornecem os objetos para a discussão e à pesquisa das Ciências Teóricas, mediados pelas Ciências da Revisão que cumprem a função de adaptar o conhecimento teórico às necessidades das ciências menos teóricas. As ciências de corpo teórico menor ou aplicado são fundamentadas na discussão e na resolução de problemas práticos da vida dos homens. A título de ilustração, a relação entre Ciências Teóricas e Aplicadas é idealizada mais recentemente por Mario Bunge (1989).

Tratará-se de resumir, com todas as faltas que isso comete, a definição das duas áreas e apresentar a relação existente entre elas e, porque, segundo o conjunto de autores relacionados, a Biblioteconomia e a Ciência da Informação são incluídas neste artigo no ramo das Ciências Aplicadas na classificação peirceana. Nesse sentido, a Biblioteconomia e a Ciência da Informação são olhadas como Ciências Aplicadas. Em síntese, elas procuram solucionar problemas enfrentados pelos usuários da informação, pelos profissionais que buscam melhores meios de coletar, organizar, armazenar (indexar, classificar e estocar), recuperar e disseminar a informação, bem como administrar e gerenciar os serviços e as unidades de informação.

A Biblioteconomia é a área que implementa procedimentos mais tradicionais se comparada à Ciência da Informação. As atividades biblioteconômicas iniciaram dentro das instituições bibliotecas, e podem ser verificadas pelas ações de: desenvolvimento de coleções, incluindo seleção e aquisição, classificação, catalogação, referência (atendimento), pesquisa a sistemas de recuperação de informação e da administração e gerência (planejamento, estudo, educação de usuário e outras) (DIAS, 2000, p. 71). 
Há também, na literatura, discursos que enfatizam a relação de similaridade entre a Biblioteconomia e a Ciência da Informação e outros como Saracevic (1996) que exclui a idéia de similaridade entre as duas áreas. Segundo esse autor, a Ciência da Informação estabelece relações com diversas áreas ou campos do conhecimento, entre as áreas estão: a Biblioteconomia, a Ciência da Computação, as Ciências Cognitivas e a Comunicação. Nesse sentido, a Biblioteconomia não tem nada a ver com a Ciência da Informação, é apenas um campo que contribui com teorias e técnicas para o trabalho de pesquisa da informação, pois até mesmo as agendas de pesquisa das duas áreas são diferentes, os temas de pesquisas da Ciência da Informação são bem diferentes dos tópicos investigados pela Biblioteconomia, sendo “[...] válido para todos os países que têm pesquisas financiadas nas áreas de CI e de biblioteconomia" (SARACEVIC, 1996, p. 49).

A Biblioteconomia, como área de estudo correlata à Ciência da Informação, não se encontra como uma subdivisão da Ciência da Informação, ela apresenta-se mais na condição de parceira ou como contribuidora, além disso, em nossa visão, a relação e os intercâmbios entre Biblioteconomia e Ciência da Informação são mais fortes, freqüentes e íntimos, principalmente no Brasil, do que é para Saracevic (1996). Na origem da Ciência da Informação foi necessário o emprego e o aperfeiçoamento de técnicas biblioteconômicas, como foi o caso da Documentação que construiu novas técnicas e métodos para os centros de documentação das organizações. Conforme Dias (2000, p. 73), a Documentação traçou sua origem no:

[...] movimento dos bibliotecários norte-americanos que trabalhavam em bibliotecas de empresas e do comércio e que resolveram fundar a Special Libraries Association, desligando-se assim da Americam Library Association $(A L A)$, a que pertenciam todos os bibliotecários, indistintamente. (DIAS, 2000, p. 73)

Barbosa et al. (2000, p. 84) e Smit, Tálamo e Kobashi (2003) esboçam uma escala evolutiva da Ciência da Informação dizendo que, a Biblioteconomia antecede a Documentação que é a predecessora da Ciência da Informação. A Biblioteconomia detém-se em dar acesso aos registros da biblioteca, a Documentação abrange todos os locais e documentos, principalmente os especializados, já a Ciência da Informação seria a evolução da Documentação. 
A Ciência da Informação possui um enfoque prático e pode ser mais bem compreendida a partir de explicações históricas deste tipo. A origem da Ciência da Informação está relacionada também com a explosão da informação e do conhecimento sistematizado. "A Ciência da Informação teve seu aparecimento e expansão no após-guerra, principalmente a partir de 1950, quando pesquisas e documentos mantidos fora do fluxo normal de informação foram liberados para o conhecimento coletivo" (BARRETO, 2002, p. 101). Também para Le Coadic (1996), o fato do crescimento do volume de informação foi primordial para o surgimento e o desenvolvimento da Ciência da Informação. O uso da informação em escalas cada vez maiores exigiu serviços mais ágeis, a demanda por informação vinha de vários setores da sociedade, das instituições tradicionais e do setor industrial.

Para que o armazenamento e o acesso à informação fossem agilizados foi necessário o uso de tecnologias de processamento de dados. Com o "[...] surgimento das tecnologias eletrônicas (analógicas ou digitais) e fotônicas da informação (microcomputadores, telas de monitor sensíveis ao toque, discos laser, fibras ópticas, dispositivos de multimídia, videodiscos, programas de gerenciamento de acervos, etc)" (LE COADIC, 1996, p. 20), as bibliotecas e as outras instituições deixaram de ser depósitos para se tornarem centros de informação. Isto evidencia o papel das tecnologias na transformação das instituições e no surgimento de uma Ciência da Informação calcada nas tecnologias de processamento de dados e nas técnicas de controle da informação. Outro fato, é que a Ciência da Informação, para Le Coadic (1996, p. 19-21), sustenta-se em uma indústria da informação que, por sinal, a legitima. Conforme o autor, a Ciência da Informação é uma ciência social e preocupa-se com a solução e o estudo de um problema prático e "[...] social concreto, o da informação, e voltada para o ser social que procura informação, coloca-se no campo das ciências sociais (das ciências do homem e da sociedade), que são o meio principal de acesso a uma compreensão do social e do cultural" (LE COADIC, 1996, p. 21).

Borko (1968) considera a Ciência da Informação como a disciplina que pesquisa as propriedades, o comportamento, os fluxos e os meios de processamento da informação para otimizar o acesso e o uso.

Wersig (1993) defende a Ciência da Informação como ciência pós-moderna e modelada para a resolução de problemas causados pelas ciências clássicas. A orientação da Ciência da 
Informação deve abarcar necessariamente a resolução de problemas sociais e não buscar saber como o mundo funciona, tópico essencial nas ciências clássicas.

Esses problemas que a Ciência da Informação intenta solucionar tornam notório seu caráter eminentemente prático, inserindo-se nas dificuldades enfrentadas por todos os tipos de unidades de informação e de suas instituições.

Outra perspectiva, é que a Ciência da Informação pode ser concebida como os estudos dos métodos e procedimentos que visam compreender e potencializar a transferência da informação para a construção do conhecimento, principalmente científico. Assim, a Ciência da Informação atua na soleira da ciência e tecnologia em diversas áreas, da produção, passando pela sistematização dos conhecimentos até chegar na distribuição dessa informação científica e técnica. Segundo Dias (2000, p. 76-77) esta é a visão que melhor enquadra-se no contexto desse campo de conhecimento.

As características da Ciência da Informação foram propostas por Saracevic (1996, p. 42), segundo ele, em primeiro lugar, a Ciência da Informação tem natureza interdisciplinar, em segundo lugar, a Ciência da Informação está estritamente ligada à tecnologia de informação tendo uma posição imperativa e determinante na área, e, por último, é peça importante na construção da sociedade da informação. Saracevic (1996, p. 47) define a Ciência da Informação como:

[...] um campo dedicado às questões científicas e à prática profissional voltadas para os problemas da efetiva comunicação do conhecimento e de seus registros entre seres humanos, no contexto social, institucional ou individual do uso e das necessidades de informação. No tratamento destas questões são consideradas de particular interesse as vantagens das modernas tecnologias informacionais.

Nesse fragmento retirado do discurso de Saracevic (1996), a referência às questões científicas revela o caráter de uma ciência reduzida aos aspectos práticos e instrumentais, servindo de auxilio à comunicação humana, não é mais nem Ciência Aplicada, no sentido de reflexão de assuntos particulares, é uma prática de resolução de problemas e de melhoria contínua.

A interdisciplinaridade, teórica ou prática, confirma o resgate de conhecimentos de outras ciências condensadoras e revisoras, para que sirvam de aplicação à Ciência da Informação. 
Essa interdisciplinaridade da Ciência da Informação é demonstrada por Le Coadic (1996, p. 23) quando este lista as disciplinas que apóiam-se na Ciência da Informação: psicologia, lingüística, sociologia, informática, matemática, lógica, estatística, economia, direito, política, eletrônica e telecomunicações, filosofia e história. Saracevic (1996) privilegia a Biblioteconomia, a Ciência da Computação, as Ciências Cognitivas e a Comunicação como áreas fundamentalmente relevantes para a Ciência da Informação. Cada disciplina estabelece maior ou menor grau de influência, dependendo do núcleo de estudo da Ciência da Informação. Se o objeto de investigação é o estudo das necessidades de informação, a psicologia e a sociologia serão as mais procuradas para consulta e intercâmbio de conceitos e informação. No caso de produzir um novo produto documentário direcionado a um público específico, as disciplinas que melhor servirão serão a lingüística e a ciência da computação.

Como a Ciência da Informação, a Biblioteconomia, também procura noutras áreas do conhecimento teorias e práticas que supram suas necessidades e solucionem os problemas de seus profissionais. Como afirmam Mostafa; Lima e Maranon (1992, p. 216) "Sociologia e Psicologia são as duas áreas de conhecimento em que a Biblioteconomia e Ciência da informação vão buscar referencial não só teórico, mas também prático para realizar algumas de suas descobertas". De forma geral, a Biblioteconomia resgata da sociologia o quadro teórico funcionalista e da psicologia traz a experimentação científica que necessita, fornecida pela abordagem comportamental-behaviorista.

A própria diversidade na formação dos profissionais que procuram resolver problemas de informação justifica a idéia de interdisciplinaridade. Saracevic (1996, p. 48-49) acredita que as disciplinas que contribuem para o desenvolvimento da Ciência da Informação estão especializando-se cada vez mais, afirmando que o envolvimento das disciplinas continua evoluindo.

A interdisciplinaridade foi introduzida na CI pela própria variedade da formação de todas as pessoas que se ocupam com os problemas descritos. Entre os pioneiros havia engenheiros, bibliotecários, químicos, lingüistas, filósofos, psicólogos, matemáticos, cientistas da computação, homens de negócio e outros vindos de diferentes profissões ou ciências. Certamente, nem todas as disciplinas presentes na formação dessas pessoas tiveram uma contribuição igualmente relevante, mas essa multiplicidade foi responsável pela introdução e permanência do objetivo interdisciplinar na CI. (SARACEVIC, 1996, p. 48). 
O ajuntamento de disciplinas e de categorias profissionais diversas tanto na Ciência da Informação quanto na Biblioteconomia conserva como finalidade: resolução e redução de problemas práticos de informação. Isto pode ser verificado, por exemplo, nas definições da Ciência da Informação, tanto as clássicas quanto as atuais que trazem expressões do tipo: “máxima utilidade dos registros”, "máximo acesso", "máximo uso da informação".

Le Coadic (1996, p. 14-15), tratando da Biblioteconomia, a define como uma prática de organização da biblioteca que responde pelos problemas relativos: ao acervo (formação, desenvolvimento, classificação, catalogação, conservação), à biblioteca como serviço organizado (regulamentos, contabilidade e mobiliário) e aos usuários (legislação dos deveres do pessoal e do público, acesso ao acervo e empréstimo). Em oposição a esta definição, tem a de Barbosa et al. (2000, p. 88) que tratam de justificar o nome de Ciência da Informação para substituição do nome da Escola de Biblioteconomia da Universidade Federal de Minas Gerais (UFMG), fundamentando que, “[...] na atualidade, a biblioteconomia lida com a informação em diferentes contextos e não apenas com livros no ambiente biblioteca". A primeira definição traz claramente o atributo prático e aplicado, a segunda consideração é uma atitude afirmativa de identificação de grupo, mas que possui na expressão "a biblioteconomia lida" a característica de esforço, de ação, de trabalho e de prática, trazendo o aspecto aplicado da Biblioteconomia.

Além da Biblioteconomia, existem outras áreas do conhecimento que também se imbricam com a natureza interdisciplinar da Ciência da Informação e igualam-se a ela no quesito - dar suporte às diversas áreas do conhecimento com o objetivo maior de resguardar e disseminar as várias formas da informação. Nesse caso, encontra-se a Arquivologia, que nas palavras de Esposel apud Fonseca (2002, p. 162) é “[...]'uma disciplina auxiliar da administração e da história, que se refere à criação histórica, organização e função dos arquivos e seus fundamentos legais e jurídicos'[...]". Diferente da Biblioteconomia e principalmente da Ciência da Informação, a Arquivologia ainda não se assentou no discurso científico de priorizar a informação como objeto de estudo (FONSECA, 2002, p. 103).

Assim, para a compreensão da Ciência da Informação e da Biblioteconomia é preferível passar por discussões que tragam à tona as interações e as relações entre estas duas áreas e as demais áreas do conhecimento. Peirce, como visto nas duas seções iniciais, ao elaborar sua 
taxionomia das ciências teve como foco a interdependência das ciências e suas relações na busca do conhecimento. A figura 1 (Diagrama das Ciências) mostra as ciências consideradas por Peirce, com a inclusão evidentemente da Ciência da Informação e a Biblioteconomia dentro do ramo das Ciências Aplicadas, que segundo os poucos teóricos analisados, acreditase que possuem as devidas características para este enquadramento.

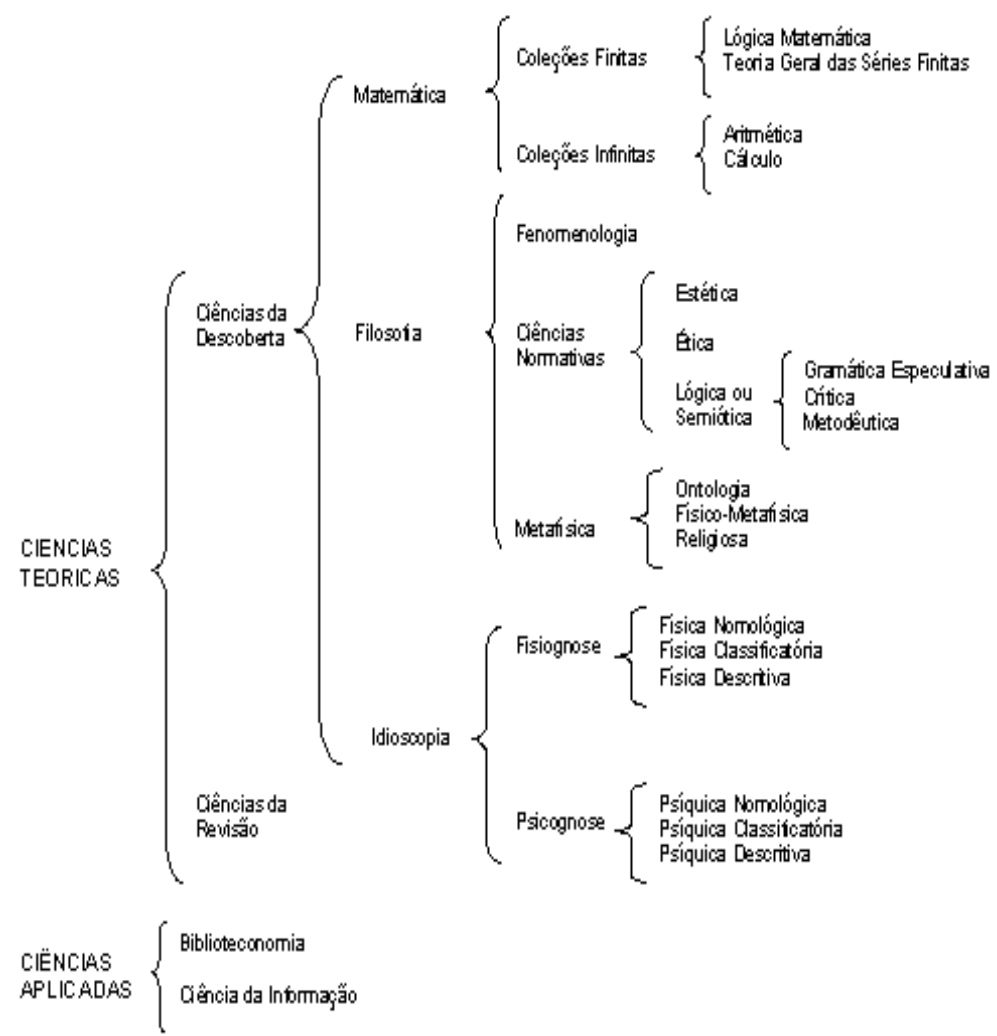

FIGURA 1: Diagrama das Ciências

Fonte: Adaptado de PIRES (1999, p. 21).

\section{CONSIDERAÇÕES FINAIS}

A Biblioteconomia e a Ciência da Informação, conforme a breve apresentação, têm caracteres de Ciências Aplicadas, que para Peirce são as que operam no espaço dos estudos de casos isolados e aplicados do conhecimento originado nas ciências que visam à generalidade e aos fundamentos últimos, as Ciências Teóricas (da Descoberta e da Revisão).

Da proposta de Peirce pode-se reter a não equivalência entre as Ciências Teóricas e as Ciências Aplicadas, no entanto existe uma interdependência que se configura nos dois 
principais ramos da taxionomia das ciências, com o auxílio de ciências ou teorias do tipo das Ciências da Revisão.

Autores contemporâneos convergem com as relações anunciadas entre as ciências feitas por Peirce, é o caso de Mario Bunge (1989). Entretanto, o resgate da filosofia de Charles Sanders Peirce, da sua contribuição para a classificação e a definição do papel das ciências, é sugestivo se o objetivo é encontrar precursores que elaboraram construções a respeito da ciência, como constituída de homens e acontecendo em movimento. Tentativa que reduz as reificações atribuídas ao conhecimento científico. De modo particular, a taxionomia das ciências peirceana contribui para se visualizar o movimento da ciência, incluir o sujeito na análise e fornecer uma visão panorâmica do conjunto das ciências da sociedade e sua relação com o universo fenomênico.

\section{REFERÊNCIAS}

ALMEIDA, Carlos Cândido de. Semiótica, Internet e interatividade: a interatividade dos portais BOL e UOL. 2003. 204 f. Trabalho de Conclusão de Curso (Graduação em Biblioteconomia) - Departamento de Ciências da Informação, Universidade Estadual de Londrina, Londrina, PR.

ANDRADE, Zilda Aparecida Freitas de. Interatividade e relacionamento virtual: um estudo em home pages de consultorias de relações públicas. 2001. 148 f. Dissertação (Mestrado em Comunicação e Semiótica) - Pontifícia Universidade Católica de São Paulo, São Paulo.

BARBOSA, Ricardo Rodrigues et al. Novo nome e novo paradigma: da biblioteconomia à ciência da informação. Perspectiva em Ciência da Informação, Belo Horizonte, v. 5, n. especial, p. 81-91, jan./jun. 2000.

BARRETO, Aldo de Albuquerque. O Tempo e o espaço da ciência da informação. Transinformação, Campinas, v. 14, n. 1, p. 17-24, jan./jun. 2002.

BORKO, H. Information science: what is it? American Documentation, Washington, v. 19, n. 1, p. 3-5, jan. 1968 .

BUNGE, M. Ciência e desenvolvimento. Belo Horizonte: Itatiaia; São Paulo: EDUSP, 1989. (Coleção O Homem e a Ciência, 11).

. Epistemologia: curso de atualização. São Paulo: T. A. Queiroz; EDUSP, 1980. (Coleção Biblioteca de Ciências Naturais; v. 4).

COELHO, Teixeira. Semiótica, informação e comunicação: diagrama da teoria do signo. 5. ed. São Paulo: Perspectiva, 1999. (Coleção Debates; 168). 
CORREIA, Claudio Manoel de Carvalho. Observações sobre o desenvolvimento histórico da psicolingüística sob a ótica do sistema peirceano das ciências. In. ENCONTRO DE PÓS GRADUAÇÃO, 2., 2002. São José dos Campos, SP. Anais... São José dos Campos, SP: UniVap, 2002. v. 1. p. 346-350.

DIAS, Eduardo Wense. Biblioteconomia e ciência da informação: natureza e relações. Perspectiva em Ciência da Informação, Belo Horizonte, v. 5, n. especial, p. 67-80, jan./jun. 2000.

FONSECA, Maria Odila. Ciência da informação: denominação de curso e diretrizes curriculares. Transinformação, Campinas, v. 14, n. 1, p. 101-104, jan./jun. 2002.

GOMES, Henriette Ferreira. O ambiente informacional e suas tecnologias na construção dos sentidos e significados. Ciência da Informação, Brasília, v. 29, n. 1, p. 61-70, jan./abr. 2000.

IBRI, Ivo Assad. Kósmos Noētós: a arquitetura metafísica de Charles S. Peirce. São Paulo: Perspectiva, Hólon, 1992. (Coleção estudos; v. 130).

LE COADIC, Yves-François. A ciência da informação. Brasília, DF: Briquet de Lemos/Livros, 1996.

MACHADO, Irene. Comunicação, um problema semiótico? [s. 1.]: [s. n.], 2001. Disponível em: <http://www.uff.br/mestcii/irene1.htm>. Acesso em: 06 ago. 2002.

MATTELART, Armand; MATTELART, Michèle. Histórias das teorias da comunicação. 3. ed. São Paulo: Loyola, 2000.

MIRANDA, Antônio; BARRETO, Aldo de Albuquerque. Pesquisa em ciência da informação no Brasil: síntese e perspectiva. Revista de Biblioteconomia de Brasília, Brasília, v. 23/24, n. 3, p. 277-292, 1999/2000. (Especial).

MOSTAFA, Solange Puntel; LIMA, Ademir Benedito Alves de; MARANON, Eduardo Ismael Murguia. Paradigmas teóricos da biblioteconomia e ciência da informação. Ciência da Informação, Brasília, v. 21, n. 3, p. 216-222, set./dez. 1992.

NEHMY, Rosa Maria Quadros et al. A ciência da informação como disciplina científica. Perspectiva em Ciência da Informação, Belo Horizonte, v. 1, n. 1, p. 9-25, jan./jun. 1996.

PEIRCE, Charles Sanders. Escritos coligidos. 2. ed. São Paulo: Abril Cultural, 1980. (Coleção Os Pensadores).

. Semiótica. 3. ed. São Paulo: Perspectiva, 2000.

. Semiótica e filosofia. São Paulo: Cultrix, 1972.

PIMENTA, Francisco Paoliello. Duas tendências em semiótica. Lumina, [s. 1.], v. 1, n. 1, p. 77-84, jul./dez. 1998. 
PINTO, Júlio. Semiótica e informação. Perspectiva em Ciência da Informação, Belo Horizonte, v. 1, n. 1, p. 87-92, jan./jun. 1996.

PIRES, Jorge Luiz Vargas P. de Barros. Panorama sobre a filosofia de Charles Sanders Peirce. Revista Cultural Fonte, Londrina, v. 2, n. 1, p. 17-33, nov. 1999.

SANTAELLA, Lúcia. As três categorias peircianas e os três registros lacanianos. Psicologia USP, São Paulo, v. 10, n. 2, 1999. Disponível em: $<$ http://www.scielo.br/scielo.php?script=sci_arttext\&pid=S0103-6564199900020 0006\&lng=pt\&nrm=iso $>$. Acesso em: 10 jul. 2002.

A teoria geral dos signos: como as linguagens significam as coisas. São Paulo: Pioneira, 2000.

O que é semiótica? São Paulo: Brasiliense, 1983. (Coleção primeiros passos; 103).

SARACEVIC, Tefko. Ciência da informação: origem, evolução e relações. Perspectiva em Ciência da Informação, Belo Horizonte, v. 1, n. 1, p. 41-62, jan./jun. 1996.

SILVEIRA, Lauro Frederico Barbosa da. A necessidade do acaso: um convite ao diálogo filosófico. Trans/ Form/ Ação, São Paulo, v. 20, p. 107-114, 1997.

. Charles Sanders Peirce: ciência enquanto semiótica. Trans/ Form/ Ação, São Paulo, v. 12, p. 71-84, 1989.

. Charles Sanders Peirce e a contemporânea filosofia da ciência: uma difícil conversação. Trans/ Form/ Ação, São Paulo, v. 16, p. 63-82,1993.

. Cosmos evolutivo e plano da criação na filosofia peirceana. Trans/ Form/ Ação, São Paulo, v. 8, p. 1-24, 1985.

. Na origem está o signo. Trans/ Form/ Ação, São Paulo, v. 14, p. 45-52, 1991.

. Origem do cosmos e auto-organização na obra de Charles Sanders Peirce. In: D’otTaviano, I. M. L. e GONZALES, M. E. Q. (Orgs.) Auto-organização: estudos interdisciplinares. Campinas: UNICAMP, FAPESP, 2000. (Coleção CLE; v. 30). Cap. 14, p. 325-336.

Pensamento, fenômeno experimental e experimento na proposta pragmatista. Trans/ Form/ Ação, São Paulo, v. 7, p. 49-59, 1984.

SMIT, J. W.; TÁLAMO, M. F. G. M.; KOBASHI, N. Y. A determinação do campo científico da ciência da informação: uma abordagem terminológica. In. ENCONTRO NACIONAL DE PESQUISA EM CIÊNCIA DA INFORMAÇÃO, 5., 2003, Belo Horizonte. Anais... Belo Horizonte: UFMG, 2003. 1 CD-ROM.

VALENTE, Nelson; BROSSO, Rubens. Elementos de semiótica: comunicação verbal e alfabeto visual. São Paulo: Panorama, 1999. (Coleção Universidades). 
WERSIG, G. Information science: the study of postmodern knowledge usage. Information Processing \& Management, v. 29, n. 2, p. 229-239, 1993.

\section{Carlos Cândido de Almeida}

Bacharel em Biblioteconomia pela Universidade Estadual de Londrina (UEL).

Telefone: (43) 3347-1420

E-mail: karl_almeida@hotmail.com; karl almeida@yahoo.com.br

Artigo aceito para publicação em: 04/ 2005 